Meta

Journal des traducteurs

Translators' Journal

\title{
Presencia y utilización de la traducción en la prensa española
}

\section{María José Hernández Guerrero}

Volume 56, numéro 1, mars 2011

URI : https://id.erudit.org/iderudit/1003512ar

DOI : https://doi.org/10.7202/1003512ar

Aller au sommaire du numéro

Éditeur(s)

Les Presses de l’Université de Montréal

ISSN

0026-0452 (imprimé)

1492-1421 (numérique)

Découvrir la revue

Citer cet article

Hernández Guerrero, M. J. (2011). Presencia y utilización de la traducción en la prensa española. Meta, 56(1), 101-118. https://doi.org/10.7202/1003512ar

\section{Résumé de l'article}

La presse écrite espagnole se nourrit du flot des informations qui circulent à l'échelle planétaire. Ces informations, traduites localement par la rédaction des principaux journaux, subissent des changements importants qui dépendent de la politique de chaque média. Le présent article est centré sur l'interaction existant entre journalisme et traduction grâce à une analyse de la présence de traductions et du processus traductionnel dans la presse espagnole généraliste. Appliquant le principe journalistique des six questions à notre analyse, nous cherchons à savoir qui traduit, ce qu'on traduit, quand, où, comment et pourquoi on traduit. Une septième question consistera à s'interroger sur la place occupée par la traduction. 


\title{
Presencia y utilización de la traducción en la prensa española
}

\author{
MARÍA JOSÉ HERNÁNDEZ GUERRERO \\ Universidad de Málaga, Málaga, España \\ mjhernandez@uma.es
}

\begin{abstract}
RÉSUMÉ
La presse écrite espagnole se nourrit du flot des informations qui circulent à l'échelle planétaire. Ces informations, traduites localement par la rédaction des principaux journaux, subissent des changements importants qui dépendent de la politique de chaque média. Le présent article est centré sur l'interaction existant entre journalisme et traduction grâce à une analyse de la présence de traductions et du processus traductionnel dans la presse espagnole généraliste. Appliquant le principe journalistique des six questions à notre analyse, nous cherchons à savoir qui traduit, ce qu'on traduit, quand, où, comment et pourquoi on traduit. Une septième question consistera à s'interroger sur la place occupée par la traduction.
\end{abstract}

\begin{abstract}
The Spanish written press is nourished by the information flow which circulates on a global level. This information, translated for local readers by the editorial departments of the leading newspapers, undergoes significant changes depending on the politics applied by each publication. This work investigates in depth the connection existing between journalism and translation by analysing the existence and use of translation in the Spanish general news press. Using the journalistic simile of the six questions and applying them to the use of translation in the Spanish press, we intend to respond to questions like: what is translated, who translates, when, where and why are translations being done, how and-adding a seventh-how much.
\end{abstract}

\section{MOTS-CLÉS/KEYWORDS}

presse, journalisme, nouvelles, diffusion internationale des nouvelles, presse écrite espagnole

press, journalism, news, international news transmission, Spanish written press

La traducción desempeña un papel crucial en la transmisión del flujo informativo a nivel global. Es pieza clave del proceso de globalización en el que estamos inmersos y una parte esencial en el proceso de producción de noticias que llevan a cabo los medios de comunicación de masas. Con la internacionalización de la información, el flujo informativo atraviesa fronteras a lo largo y ancho del globo en un complejo proceso de comunicación transcultural sólo posible gracias a la traducción. La globalización no ha hecho más que acentuar esta tendencia, que se ha visto agilizada por el auge de las nuevas tecnologías de la información.

Este fenómeno es fácilmente observable en todos los medios de comunicación a nivel mundial. Los medios españoles no son una excepción; un porcentaje importante de la información que se produce en España es información traducida. La prensa escrita española, en particular, se nutre, en una parte nada desdeñable, del caudal informativo que circula a escala planetaria, hasta el punto de poder afirmar que 
estamos ante una de las prensas europeas que más recurre a la traducción. El estrecho vínculo que une la actividad periodística con la traductora no ha hecho más que intensificarse en la era de la información para convertirse en lo que, sin temor a exagerar, podríamos denominar una auténtica dependencia, pues en la actualidad sería muy difícil concebir el periodismo sin la traducción.

Hemos de ser conscientes de que la denominación prensa española comprende multitud de publicaciones de muy diversa índole: prensa generalista, especializada, diarios de ámbito local, regional o nacional, revistas, suplementos semanales..., que suponen un desmesurado campo de análisis, que nos hemos visto obligados a acotar. Nos centraremos aquí en las publicaciones más representativas y de más peso del panorama periodístico español: los grandes diarios de información general de tirada nacional (tipo El País, El Mundo, ABC, La Vanguardia...).

La práctica de la traducción en el ámbito periodístico, también conocida como traducción periodística, ha sido objeto de análisis por parte de diferentes investigadores en el ámbito cultural hispánico (Tapia Sasot de Coffey 1992; Gutiérrez de Terán 1997; Martínez 2001; Stinson de Quevedo 2001; Cortés Zaborras y Hernández Guerrero 2005). No pretendemos aquí incidir en la descripción de las características de este tipo de traducción. Nos limitaremos a señalar que la traducción periodística es una práctica profesional fuertemente marcada por los modos y exigencias que rigen en el ejercicio del periodismo y por el marco lingüístico propio de cada comunidad cultural -que se concreta en sus géneros periodísticos y en el estilo que establece cada publicación-, factores estos que determinan el modo en que se utiliza y se lleva a cabo la traducción. Siempre con una particularidad: la labor puramente lingüística se ve supeditada a la labor informativa.

Lo que sí pretendemos es profundizar en la conexión existente entre periodismo y traducción, a través del análisis de la presencia y utilización de la traducción en un contexto cultural preciso y en un tipo de publicación representativo: la prensa española de información general. Utilizando el símil periodístico de las seis preguntas, orientado al estudio del uso de la traducción en la prensa española, queremos responder a cuestiones del tipo: qué se traduce, quién traduce, cuándo, dónde, por qué se traduce, cómo y -añadiendo una séptima- cuánto.

\section{1. ¿Qué se traduce?}

El material traducido que la prensa precisa para sacar adelante sus ediciones no deja de aumentar día tras día. La entrevista del corresponsal en Nueva York al secretario general de Naciones Unidas, las últimas noticias de agencia que llegan sobre el conflicto de Afganistán, los artículos de opinión de conocidos analistas internacionales o la reproducción de algún reportaje procedente de otro medio europeo o estadounidense, son sólo muestras de producción periodística que no habría sido posible sin recurrir a la traducción. En palabras de José Manuel Vidal (2005: 388), periodista traductor del diario El Mundo, en la prensa española "se traduce absolutamente de todo y para todas las secciones del periódico: desde internacional a sociedad, pasando por economía o deportes". Con todo, existen determinadas secciones de la prensa española donde se observa una mayor utilización de la traducción: en concreto la sección de Internacional y la de Opinión (Hernández Guerrero 2005a). 
A pesar de que la actividad traductora en la prensa escrita española es constante, su presencia, sin embargo, no es visible, pues el flujo incesante de material traducido se diluye y se entremezcla, en el proceso de generación de nueva información, con el material periodístico que se produce en las redacciones, pasando a formar parte de la producción propia de los medios. Además, las maneras de servirse de la traducción no son uniformes, lo que da lugar a prácticas traductoras variadas que engloban desde el tradicional texto traducido que reproduce fiel e íntegramente el contenido del original, a otros usos de la traducción más difusos donde la noción clásica del término resulta difícil de aplicar. La utilización por parte del periodismo de estas prácticas traductoras multiformes ha recibido escasa atención de los profesionales e investigadores del ámbito periodístico, así como de los dedicados al estudio de la traducción, y ello a pesar del papel crucial que desempeña la traducción en la transmisión de los mensajes periodísticos.

A esta invisibilidad de la traducción en la prensa contribuyen las prácticas propias del marco periodístico español en lo referente a la firma de las traducciones, con una ausencia general de este tipo de marcas en algunas cabeceras (Alonso 2004, Hernández Guerrero 2005b). Igualmente, contribuye la transparencia de los textos traducidos, entendida ésta como la exigencia de fluidez que impone el lenguaje periodístico y que, en el caso de estas traducciones, se plasma en una manera de enfocar la mediación en la que los textos se adaptan a las normas de la cultura receptora, minimizando las diferencias lingüísticas y culturales en aras de la fluidez en las relaciones entre distintas comunidades.

Invisibilidad y transparencia definen, pues, la naturaleza de la traducción en la prensa española de información general y crean la sensación de que en sus redacciones no se traduce. Nada más erróneo, la actividad traductora es constante.

\section{2. ¿Quiénes traducen? y ¿dónde?}

La mayor parte del trabajo de traducción que se realiza en la prensa española la llevan a cabo los propios profesionales de los medios de comunicación. Se trata de periodistas y redactores que simultanean el quehacer periodístico con el traductor. De manera general, estos periodistas, que también traducen, no consideran esa labor como actividad traductora, sino que la perciben como labor de edición o elaboración de una noticia a partir de un texto en otra lengua. No ven que en la generación de información con fuentes en otras lenguas se produzcan dos actividades distintas, la traductora y la periodística, sino que ambas están integradas. Se ven como periodistas haciendo su trabajo y se consideran periodistas más que traductores (Frías Arnés 2005; Vuorinen 1995). Probablemente influya en ello la conexión con el prestigio: producir información se ve como un proceso que comprende toma de decisiones y creatividad, mientras que la traducción se percibe como una tarea pasiva o una imitación. Además, persiste la lógica de que la producción de un artículo es una operación periodística sujeta a factores comunicativos, mientras que la traducción -al menos el concepto de traducción que los periodistas manejan- es una operación más preocupada por el respeto del texto original que por el valor funcional del nuevo producto.

En resumidas cuentas, lo que hacen los profesionales de los medios, desde su propia óptica, no es traducción, es periodismo. Leer y quizá traducir un despacho, 
por poner un ejemplo, forma parte de la tarea cotidiana de un redactor. El periodista se define a sí mismo como un intermediario, un mediador, entre los acontecimientos y el público en una tarea compleja que le lleva a seleccionar, filtrar, reorganizar, valorar, jerarquizar, distribuir y, también, traducir las informaciones.

Este estado de cosas no puede ocultar, en cambio, que una parte importante de profesionales del periodismo realiza tareas basadas de forma única y exclusiva en la traducción; en otras palabras, el trabajo del periodista consiste llanamente en traducir. Esto sucede, en mayor medida, con los profesionales de los grandes grupos de comunicación transnacionales que, en una política de rentabilización de costes y aprovechamiento máximo de recursos, ofrecen contenidos traducidos (como, por ejemplo, en el suplemento informativo de The New York Times en español publicado por El País con contenidos exclusivos de dicho diario, la edición española de Le Monde Diplomatique...). En menor grado, simultaneando traducción y producción propia, también ocurre en el resto de los medios.

Con todo, estos profesionales rara vez se consideran traductores. Las denominaciones más aproximadas que encontramos para referirse a ellos en el marco periodístico español son del tipo periodista traductor o redactor traductor. En la jerga profesional, sin embargo, lo habitual es que se les denomine periodistas, redactores o editores.

Lo cierto es que la acelerada transformación que experimenta la prensa, con un incremento ingente de la información disponible, exige nuevos roles del periodista: tiene que ser alguien que filtre y no sólo que transmita, un organizador y un traductor, así como alguien que reúna y haga accesible los hechos. Además de saber cómo redactar informaciones de prensa o cómo contarlas para un determinado medio, también debe saber cómo llevar a cabo el trasvase transcultural. El caudal informativo fluye incesantemente y parte de él está redactado en otras lenguas, lo que implica la necesidad de traducir. Estos profesionales no sólo median entre el acontecimiento y el público, su labor es más especializada, pues comprende la mediación cultural.

Frente a este tipo de profesional, suele ser frecuente que la prensa española recurra, sistemática o esporádicamente, según el medio, a traductores autónomos (o freelance) e incluso a agencias de traducción, a los que ocasionalmente se les encarga la traducción de ciertos artículos. Un ejemplo claro lo tenemos en las traducciones que se publican en la sección de Opinión del diario El País, firmadas en su gran mayoría por traductores autónomos, que no forman parte de la plantilla del periódico. Estos textos se presentan como traducciones y suelen incluir un pie de texto con la firma del traductor y/o algún tipo de marca que deje ver la procedencia del original (caso del copyright).

El hecho de que la labor de traducción se asuma de formas distintas en cada medio hace difícil generalizar: las prácticas varían entre unos y otros. En el diario $E l$ País, por ejemplo, las traducciones las realizan tanto los periodistas de la redacción como traductores autónomos, y también se recurre a los servicios de una agencia de traducción (News Clips). En La Vanguardia la situación es parecida. Como señala López Guix (2005: 106), la traducción se realiza en la redacción por un periodista traductor o por traductores externos. Sin embargo, en el periódico El Mundo esta tarea la asumen únicamente los periodistas de la redacción (Vidal 2005).

Es preciso señalar, además, que en el ámbito de la prensa escrita española apenas si existen reflexiones de los traductores sobre la propia experiencia y las condiciones 
laborales, frente a otros ámbitos de la traducción que generan un número importante de reflexiones personales (piénsese, entre otros, en el campo literario). Una excepción son dos publicaciones -López Guix (2005) y Vidal (2005)- que recogen las experiencias de estos dos traductores (el primero como traductor autónomo para La Vanguardia y el segundo como periodista traductor en El Mundo), y, además, presentan la dinámica de traducción de esos medios, comentando los rasgos más destacados de su labor profesional.

Independientemente de quién lleve a cabo la labor de traducción, hemos de ser conscientes de que en la producción de textos periodísticos intervienen varias figuras que en mayor o menor medida determinan el producto final que se brinda a los lectores. En el ámbito periodístico se produce un "proceso de transformación colectiva del texto" (Casasús y Núñez Ladevéze 1991: 87; Martínez Albertos 2000: 198) y los textos resultantes son obra de diferentes coautores, unos con mayor responsabilidad que otros en el producto que acaba publicándose. Por ello, al referirnos al papel del traductor periodístico y su responsabilidad última como autor de la traducción, no hemos de olvidar los usos propios de este marco profesional.

Todo lo anteriormente expuesto nos permite responder al segundo interrogante de este epígrafe: ¿dónde se traduce? En el caso de la prensa española, el lugar físico donde se lleva a cabo la mayoría de las traducciones es en las propias redacciones de los periódicos. Ese marco condiciona enormemente el modo en que se lleva a cabo la traducción, que deja de ser una labor individual y autónoma para convertirse en parte del engranaje del quehacer periodístico y de la generación de nueva información. Con todo, la traducción de algunos artículos (especialmente, los artículos de opinión) se produce fuera de este marco - sin la presión y los condicionantes de la redacción del diario-, y se encarga, como hemos expuesto, a profesionales de la traducción, ya sea autónomos o trabajando para agencias.

\section{3. ¿Cómo se traduce?}

La actividad traductora en la prensa escrita española es constante, sin embargo, las maneras de servirse de la traducción no son uniformes, lo que da lugar a prácticas traductoras variadas que engloban desde el tradicional texto traducido que reproduce fiel e íntegramente el contenido del original, a otros usos de la traducción más difusos donde la noción clásica del término resulta difícil de aplicar. Y esto es así porque no todos los textos periodísticos que se generan y se han nutrido de la traducción pueden ser considerados como traducciones en el sentido estricto de la palabra; con cierta frecuencia el producto resultante no responde al concepto que tradicionalmente se tiene de texto traducido, sino que se sitúa entre las reescrituras habituales del ámbito periodístico, en un terrero indefinido (Hernández Guerrero, en prensa).

No conviene olvidar que en el contexto periodístico la labor de transformación de un texto en lengua extranjera no es arbitraria, sigue una lógica específica, tiene sus propios objetivos y su motivación: los textos son vehículos para la información y se opera sobre ellos mientras dura el largo proceso de su periplo vital, desde el emisor hasta sus receptores últimos. Los sujetos que llevan a cabo esta labor son en su mayoría periodistas, cuya tarea consiste en producir información al servicio de una empresa de comunicación, que, como iniciadora de este proceso, desempeña un papel 
determinante e influye de manera decisiva en la orientación y presentación final de estos artículos.

Estos dos tipos de condicionantes -lingüísticos y periodísticos- inciden en el modo en que se lleva a cabo la traducción en la prensa escrita.

\subsection{Condicionantes lingüísticos}

En la producción de textos periodísticos, las formulaciones estilísticas y retóricas se organizan de un modo específico. La confección de un artículo periodístico se rige por unos principios que guían, por ejemplo, la disposición de la estructura textual, de los argumentos, la sintaxis, etc. Cuando se habla de textos periodísticos se alude, en realidad, a un conjunto de tipos textuales que no es uniforme. Nos encontramos ante diferentes tipos de discurso o géneros.

Los géneros periodísticos españoles han sido ampliamente estudiados y clasificados en el ámbito académico y contamos con excelentes obras para su análisis y descripción (Casasús y Núñez Ladevéze 1991; Martínez Albertos 1989; 2000; Gomis 1991; Núñez Ladevéze 1993; 1995, entre otros). Existen distintas clasificaciones dependiendo del enfoque de los diversos autores. Siguiendo la propuesta simplificadora de Casasús y Núñez Ladevéze (1991:88), podemos distinguir tres grandes categorías: géneros informativos, interpretativos y argumentativos, que englobarían las variedades textuales presentes en la prensa escrita ${ }^{1}$.

Los géneros se diferencian entre sí por su estilo y la utilización de los recursos lingüísticos, su finalidad y la disposición psicológica del autor. Además de la estructura interna, contamos con su exterior, su imagen, la cual también es una parte fundamental de la información que los medios y los periodistas ofrecen a sus receptores. La percepción del texto periodístico (ubicación, extensión, formato, etc.) nos proporciona igualmente una información visual adicional.

Cada uno de estos géneros presenta unas convenciones textuales ya establecidas, una manera de comunicar con unas estructuras determinadas, características de la producción periodística del español peninsular. Sin embargo, los géneros periodísticos varían entre lenguas y culturas diferentes. Así, si tomamos como ejemplo la noticia, variedad textual del género informativo, veremos que presenta en español una estructura convencional, en la que destaca: (i) un tipo de titular extenso, que informa al lector de lo que ocurre sin necesidad de que éste deba recurrir al resto de la información; (ii) la entrada, que incluye lo más significativo de la información; (iii) el cuerpo de la noticia que explica, amplía y respalda lo que dice la entrada. Tradicionalmente, el contenido de la noticia se estructura siguiendo las pautas de la pirámide invertida, que supone colocar el material informativo más importante al principio y el menos relevante al final. Esta técnica se sigue aplicando, aunque convive con otras, como la estructura cronológica o narración natural de los hechos. La noticia tiene como finalidad reflejar con la mayor exactitud posible la realidad a la que ha tenido acceso el periodista. Martínez Albertos (2000: 263) destaca su estilo sobrio y escueto, rigurosamente objetivo. Estos rasgos vienen marcados culturalmente; se trata de una serie de convenciones textuales que los periodistas, por un lado, conocen y aplican, y los lectores del diario, por otro, esperan encontrar.

Los patrones que rigen la confección de una variedad textual en un sistema sociocultural determinado no tienen por qué coincidir con los patrones textuales de 
otros sistemas. Volviendo al ejemplo anterior de la noticia, si bien es cierto que los rasgos que presenta en español se encuentran igualmente en la noticia de países de nuestro entorno, también existen diferencias. Por ejemplo, no es extraño que las noticias publicadas en la prensa francesa incluyan notas a pie de página al final del artículo para ampliar algún dato, algo completamente inusual en los diarios españoles; o que la manera de titular una información difiera entre estas dos lenguas (Hernández Guerrero 2004). Así, los titulares de las noticias en español son mucho más directos, más explícitos que en francés y no admiten lenguaje figurado; transmiten, además, gran parte de la información que contienen los textos, incluyendo todos los elementos gramaticales de una frase normal. Por ello, al traducirlos al español, se modifican para adaptarlos a las convenciones que rigen para los titulares de géneros informativos (sin contar con la nueva orientación que pueden recibir las noticias traducidas en el sistema cultural de llegada), como podemos ver en el siguiente ejemplo:

(1) La Banque de France en voie au régime sec (Libération, 11-02-2003)

El Banco de Francia prevé cerrar el 75\% de su red en 10 años (El Mundo, 13-022003)

Además, las convenciones que rigen la confección de una variedad textual en un sistema sociocultural determinado no tienen por qué coincidir con los patrones textuales de otros sistemas. Por esta razón, la labor de traducción se centra en producir nuevos textos periodísticos, que se insertan en una tradición lingüística y cultural específica, que se rige por parámetros diferentes a la del original. En la producción y presentación de estos textos influye igualmente la norma propia para cada medio, recogida en los diferentes libros de estilo de los que se han dotado los diarios de prestigio. Su función principal es definir la personalidad de una publicación. Secundariamente, hacen hincapié en el uso correcto del idioma y previenen contra las infracciones más frecuentes de la norma aceptada, aportando las opciones que se han de aplicar en el periódico. Los textos que se generan mediante traducción, al igual que el resto de la producción original, deben plegarse a las normas establecidas en los libros de estilo, que determinan, por ejemplo, el sistema de trascripción de sustantivos procedentes de otros alfabetos, la actitud ante los préstamos, etc.

\subsection{Condicionantes periodísticos}

El texto que originalmente surgió en un marco espacio-temporal determinado, con una función y unos destinatarios específicos, sufre una serie de transformaciones en su trasvase transcultural y atravesará diferentes etapas de reelaboración hasta llegar a sus receptores finales en un nuevo marco comunicativo.

En lo que respecta a la prensa escrita, el lector, destinatario último del periódico, determina en gran medida el tratamiento que reciben todos los artículos, incluido los traducidos. Como empresa de comunicación, el diario busca su rentabilidad y una de sus fuentes de ingresos es la venta de ejemplares. En el complejo mapa de la prensa española, los lectores tienen a su disposición una amplia oferta y la elección de uno u otro producto viene determinada por distintos factores: económicos, ideológicos, culturales, lingüísticos... En un mercado tan competitivo, las cabeceras luchan por atraer a nuevos compradores y fidelizarlos; entre sus estrategias se encuentra la 
defensa de una determinada línea editorial, de un cierto posicionamiento político, que, más allá de la tan cacareada independencia, atrae a grupos de lectores que se identifican con ese modo de pensamiento y ven refrendado su sistema de valores o creencias. Esos receptores finales, afines a la política editorial del medio, determinan en gran medida el proceso de selección de información, el contenido de ésta y qué políticas de traducción se llevan a cabo.

El formato de cada periódico también influye en el tratamiento que recibe la información traducida. Los medios escritos ofrecen la información con un diseño formal propio, un conjunto en el que la forma y el contenido aparecen estrechamente unidos y que constituye un punto de referencia para su público. El formato de un periódico refleja el valor que éste otorga a la información que publica en una especie de código interno que sus lectores han aprendido a interpretar. En lo que respecta a las traducciones, afecta a cuestiones como la extensión (los textos tienen asignados espacios determinados), dando lugar en ocasiones a cambios relevantes. Pero más importante aún es la función que el nuevo canal otorga al artículo traducido. El texto puede mantener o variar la función con la que fue concebido. Al mismo tiempo, de esa función dependerá su ubicación (puede aparecer en una sección distinta: un artículo publicado en la sección de noticias nacionales puede ser traducido para la sección de Internacional de otro periódico). Además, una información relevante que fue cubierta de manera extensa por la cultura emisora puede tener una extensión menor en la cultura receptora, donde el tema no se considere de tanto interés o, todo lo contrario, una información breve puede ser ampliada. Los originales se utilizan, pues, para producir nueva información en español que se ha de presentar como artículo periodístico de un diario a un nuevo lector y ha de acomodarse a la línea editorial del medio que lo acoge. Todo ello da pie a prácticas traductoras muy variadas, que, en ocasiones, dan lugar a productos que no responden al concepto tradicional de texto traducido, pues en el ámbito informativo se lleva a cabo un uso de la traducción muy específico (cf. los análisis de traducciones llevados a cabo en Hernández Guerrero 2006 y en prensa).

Los hábitos profesionales también marcan el modo en que se realiza la traducción periodística: en la prensa escrita es habitual que traducción y edición se lleven a cabo de manera simultánea. Las tareas de traducción siempre han comprendido una cierta dosis de edición: hay que ocuparse de cuestiones como qué modificar, añadir o quitar, cómo aumentar la claridad; llevar a cabo la reorganización del texto, una determinada adaptación ideológica o cultural, o introducir los cambios necesarios para que se respeten las convenciones textuales. El término transedición, acuñado por Stetting (1989), designa la combinación de traducción y edición cuando la actividad traductora "se centra específicamente en las necesidades de los receptores de la traducción", que, por supuesto, depende en cierta medida de la función que deben cumplir los textos traducidos. Este tipo de tarea requiere del profesional una mayor competencia y le hace asumir otro tipo de responsabilidad en el proceso de transferencia.

En los diarios españoles la transedición es una labor habitual. Los redactores tienen que manejar material en otras lenguas y procesar esa información para los artículos que escriben. En otras ocasiones, tienen que traducir artículos; conocen de antemano el espacio del que disponen y la función que deben cumplir los textos y en esta tarea tienen que emplear grandes dosis de edición para adaptarlo al nuevo medio y a los nuevos receptores, algo que en el quehacer periodístico es habitual que se 
realice en un único proceso. Sin embargo, la transedición por sí sola no puede explicar las importantes transformaciones que se observan en la información traducida.

\subsection{Localización}

Los condicionantes lingüísticos y periodísticos a los que antes aludíamos hacen que los textos traducidos en la prensa sufran un alto grado de manipulación. Para hacernos una idea, de las 56 noticias traducidas de otros diarios europeos que publicó $E l$ Mundo en su sección de Internacional durante el año 2006 (para un análisis detallado de estos datos, cf. Hernández Guerrero 2010), sólo un pequeño porcentaje (13 traducciones, el 23\% del total) se limitaba a reproducir únicamente el contenido del original, como podemos observar en la siguiente tabla:

TABLA 1

Tipos de prácticas traductoras utilizadas en las noticias traducidas en la sección de Internacional del diario El Mundo en el año 2006

\begin{tabular}{|l|c|c|}
\hline Transferencia completa simple & 13 & $23 \%$ \\
\hline Transferencia completa con amplificación & 2 & $3 \%$ \\
\hline Transferencia completa compilada & 6 & $11 \%$ \\
\hline Transferencia parcial & 24 & $43 \%$ \\
\hline Transferencia parcial compilada & 5 & $9 \%$ \\
\hline Reescritura & 6 & $11 \%$ \\
\hline
\end{tabular}

Un porcentaje muy elevado de los textos de este corpus (el 77\%) presentaba algún tipo de manipulación. El considerable grado de transformación que experimenta la información traducida ha llevado a investigadores como Pym (2004) y Orengo (2005), a extender la noción de localización al ámbito de la traducción periodística. Al igual que otros productos, la noticia se disemina a través de una red global de empresas de comunicación a un número infinito de contextos locales. Los cambios que implica este proceso no se limitan a los que se producen en el trasvase lingüístico, que sólo constituyen una parte de ese complejo proceso. Para describir lo que ocurre en el proceso de transedición, hay que considerar que se produce simultáneamente un proceso de localización de la noticia en su lugar último de publicación (en este caso, el periódico español que la publica). El proceso de localización transforma el mensaje y lo adapta a las condiciones que marcan, por un lado, las empresas de comunicación y, por otro, sus nuevos usuarios, que no comparten el marco lingüístico y cultural del emisor. Al final, la noticia es local en el sentido de que es manipulada, se incorporan elementos, se adecuan, se alteran..., para encajar el texto en la nueva situación comunicativa.

\subsection{El estatus del original: fuentes estables e inestables}

El material periodístico que se traduce en la prensa escrita es muy variado: noticias, despachos de agencias, entrevistas, reportajes, crónicas, artículos de opinión... Adoptando la forma de los diferentes géneros periodísticos, ese flujo informativo circula a escala global y está a disposición de los medios, que lo seleccionan y traducen en función de sus necesidades e intereses. 
Sin embargo, la manera de trasvasar esa amplia gama de variedades textuales no es uniforme. Análisis de traducciones que hemos llevado a cabo en otros trabajos (Hernández Guerrero 2005a; 2008b; 2010), nos permiten distinguir dos maneras muy diferentes de enfocar la traducción, que dependen de la naturaleza del original:

1. Si el original se centra en la exposición de los hechos -como ocurre con los géneros informativos e interpretativos-, es considerado como una fuente inestable ${ }^{2}$. La fuente inestable se presta a una constante reescritura; los textos, en sus diferentes fases de producción, pasan por varios mediadores que cuentan con gran libertad para ponerlos al día y actualizarlos. Es habitual que en este periplo el quehacer traductor implique que los textos se abrevien o se amplíen, se les añada información o se les suprima, en un proceso de reescritura que termina por adaptarlos a las necesidades informativas de la empresa de comunicación, con todas las implicaciones que ello conlleva. El autor o los autores pasan a un segundo plano y prima la información que vehiculan sobre otras consideraciones, por lo que es frecuente que los textos traducidos sean transformados y manipulados.

2. Si el original sirve para dar a conocer las ideas o juicios de valor suscitados a propósito de hechos que han sido noticia más o menos reciente -como ocurre en el caso de los géneros argumentativos-, es considerado como una fuente estable. Los autores aquí cobran un especial protagonismo, se trata de personas que ya han alcanzado una cierta posición en sus profesiones: son firmas de prestigio. Cuando el original es una fuente estable, el texto de llegada suele ser una traducción stricto sensu. Se trata, por lo general, de textos fijos, artículos firmados, con unos determinados derechos (copyright) que restringen la libertad de acción del mediador. El texto se adapta al nuevo marco comunicativo, pero continúa siendo fiel reflejo del original. Su estatus es el de una traducción, por ello es frecuente que incluya ciertas marcas que permiten reconocerlo como tal y así es recibido en el nuevo sistema cultural.

Esta distinción simplifica en exceso las diferentes formas de uso de la actividad traductora que se observan en la prensa escrita. Con todo, resulta de gran utilidad para el análisis del fenómeno traslativo en los periódicos españoles. Estos llevan a cabo la transferencia de originales procedentes de otros sistemas culturales de manera distinta según el género periodístico de que se trate, $y$, en consecuencia, de su consideración como fuente estable o inestable.

\section{4. ¿Cuándo y por qué se traduce?}

¿Cuándo se recurre a la traducción? Generalmente cuándo las necesidades de la empresa de comunicación así lo exigen. Esas necesidades dependen de toda una serie de variables, que influyen de modo decisivo en que un medio se sirva o no de la traducción. Principalmente se trata de variables de tipo informativo, empresarial y económico, todas en estrecha interrelación. La necesidad de informar sobre gran parte de lo que acontece en el mundo es el motor que pone en marcha el mecanismo de la traducción en la prensa escrita. Se traducirá dependiendo de la política empresarial del medio y por razones económicas.

Las variables de tipo empresarial vienen determinadas por el peso de la compañía de comunicación a la que pertenece un periódico concreto: un periódico fuerte, perteneciente a un gran grupo de comunicación, dispone de muchos más recursos y fuentes de información (redactores, corresponsales, suscripciones a agencias de noticias, acuerdos con otros medios...) que otros diarios más modestos. Puede, por tanto, 
elaborar información propia a partir de sus propios recursos, algo imposible para otros medios, que se ven abocados a obtener esa misma información a través de otros canales mediante la traducción.

Esta variable empresarial se halla muy vinculada a la económica: el periódico es una empresa que busca su rentabilidad y el ahorro de costes. Servirse de la información ya elaborada, como la que suministran las agencias de noticias, o traducirla de otros medios, con los que se tienen acuerdos previos, supone una reducción de costes considerable a la que recurren frecuentemente los diarios españoles.

En el caso concreto de las noticias de agencia, material traducido en su mayor parte, Muro Benayas (2006: 71-72) distingue diferentes usos de estos productos en la prensa española según el tamaño de los diarios, señalando que la dependencia no es igual en todos ellos. Los grandes periódicos se caracterizan por una escasa publicación de las noticias de agencias, que se sitúa entre el 5 y el 10\% de lo publicado; la utilidad básica atribuida a las agencias es alertar sobre acontecimientos y facilitar las primeras respuestas hasta que el que medio obtenga nuevos datos fruto de sus iniciativas y sus propios recursos. En los diarios medianos la presencia supera el $35 \%$ y en los pequeños, entre el 60 y el $80 \%$ de lo publicado.

La manera de procesar la información de las agencias también difiere según el tamaño del diario. Los grandes medios tienen mayor capacidad de reelaborar lo recibido, que es considerado como materia prima para procesar nueva información. Muestran más reparos a la hora de reconocer de una manera clara que sus fuentes son las agencias. En los diarios medianos y pequeños, por el contrario, el grado de reelaboración es menor y el reconocimiento de las fuentes, mayor; les viene bien, pero sólo hasta cierto punto, indicar que se nutren de determinadas agencias, que aportan credibilidad a lo publicado sobre acontecimientos lejanos a su entorno.

Esta realidad salta a la vista con sólo ojear las páginas de información internacional de los diarios españoles. En ellos encontramos dos formas de utilización del caudal informativo que sirven las agencias. Por un lado, la reproducción total o parcial de la noticia suministrada y, por otro, la utilización de su contenido para generar otra información. Esta segunda modalidad da lugar a diferentes tipos de reescritura periodística que parten de material traducido para elaborar nuevas noticias de producción propia, como pueden ser la inclusión de fragmentos en otros artículos, la utilización de datos de esos despachos o la reconstrucción de los hechos y su actualización a través de la creación de una nueva noticia que se basa en los relatos suministrados por varias agencias. Esta última modalidad es, tal vez, la más visible para los lectores, pues la prensa española acostumbra a firmar estos artículos con la denominación Agencias. Aquí el periodista elabora una información a partir de diversas fuentes, en distintas lenguas; lo lee todo, señala las cosas que le parecen más interesantes y hace una información en español con material de agencias. Aunque tome los hechos de muchas agencias en varios idiomas, no deja de hacer una información en español. Los despachos de agencias que se traducen en la redacción del periódico son, a su vez, un material que previamente ha experimentado otros procesos de traducción (Bielsa y Bassnett 2008), por lo que estamos ante una doble o triple labor de mediación en la transmisión de estos mensajes.

El siguiente ejemplo puede servir de muestra de esta política de reelaboración de la información que siguen los diarios españoles: los tres rotativos de mayor tirada $-E l$ País, El Mundo y La Vanguardia- se hicieron eco, en julio de 2008, de las protestas 
que se produjeron en Belgrado por la extradición de Radovan Karadzic al Tribunal de La Haya. Reproducimos los títulos de los artículos publicados y las fuentes declaradas que se utilizaron en su producción:

(2) a. 15.000 ultranacionalistas marchan en Belgrado contra la entrega de Karadzic Agencias/P. Rusiñol El País, 30-07-2008

b. Miles de serbios apoyan a Karadzic y desafían al Gobierno David Charter The Times/El Mundo El Mundo, 30-07-2008

c. Belgrado da la espalda a Karadzic

Agencias

La Vanguardia, 30-07-2008

Ante la ausencia de un corresponsal en la zona, cada uno de ellos obtuvo la información por distintos canales. El País presenta un artículo confeccionado con material de agencias, reelaborado por un redactor en Madrid, Pere Rusiñol. El Mundo recurre a la traducción del artículo de David Charter publicado en el diario británico The Times. La Vanguardia, por su parte, elabora una información a partir de noticias de agencias. En todos los casos el lector recibe información traducida.

\section{5. ¿Cuánto se traduce?}

La escasez de reflexiones o estudios sobre el papel que desempeña la traducción en el proceso de generación de nueva producción periodística, unida a la invisibilidad de las traducciones periodísticas, no ha hecho más que aumentar la creencia de que al leer la prensa española accedemos a contenidos originales, propios del medio, cuando ciertamente, en una parte importante de los mismos, ha mediado la labor de traducción. La falta de datos sistemáticos sobre la proporción de textos traducidos que se publica en la prensa española hace difícil cuantificar el volumen de traducciones que mueve el sector y la cantidad de información traducida que publica. En ello influye notablemente la dificultad de abordar ese corpus. Los periódicos no siempre indican las fuentes de las que se sirven y la mayor parte de las traducciones se presentan sin las marcas de traducción necesarias para su identificación (nombre del traductor, procedencia del original, lengua de la que se ha traducido...). Además, los textos traducidos en la prensa adoptan generalmente un formato distinto al del texto de partida y con cierta frecuencia presentan importantes modificaciones que dificultan la localización e identificación de los originales.

Los únicos datos disponibles hasta la fecha se reducen a estudios centrados en publicaciones concretas y durante periodos de tiempo relativamente breves. Tal vez el más completo de todos sea el de González Rodríguez (1999): La traducción en la prensa: "El País, 1995", que presenta la primera aproximación cuantitativa que permite analizar el peso de la actividad traductora en un periódico generalista de prestigio durante un año. Mediante datos tangibles, recogidos en un laborioso y detallado seguimiento diario de todas las secciones de El País, este investigador, además de cuantificar el volumen de traducciones, ofrece una visión bastante certera de la importancia de la traducción en este medio.

Una primera dificultad en su labor, ante la falta de marcas de traducción, fue identificar los textos que eran claramente fruto de la traducción. González Rodríguez 
(1999: 208) consideró los siguientes: los despachos de agencias (excepto la agencia Efe), las entrevistas con personalidades extranjeras, los artículos escritos por personalidades extranjeras y los artículos firmados con el nombre de un periódico o una revista extranjera. Esta selección excluye necesariamente otros textos que, en parte o en su totalidad, se han elaborado mediante la traducción, como es el caso de noticias que llevan como firma "agencias", textos que no presentan firma y otros tipos de reescrituras que se sirven de la actividad traductora. Su estudio viene a establecer que las traducciones representaron un $12,61 \%$ del total de artículos del diario y las secciones que más traducciones publicaron en 1995 fueron, por orden de importancia, las siguientes:

TABLA 2

Porcentaje de artículos traducidos en el diario El País en 1995 por secciones. Fuente: González Rodríguez (1999)

\begin{tabular}{|l|c|l|c|}
\hline Revista de prensa & $97,01 \%$ & Comunicación & $6,25 \%$ \\
\hline Internacional & $29,62 \%$ & Deportes & $5,74 \%$ \\
\hline Debates & $23,70 \%$ & Negocios & $5,47 \%$ \\
\hline Futuro & $23,12 \%$ & Economía & $5,31 \%$ \\
\hline Opinión & $19,62 \%$ & Domingo & $4,29 \%$ \\
\hline Salud & $15,04 \%$ & Cultura & $3,63 \%$ \\
\hline Sociedad & $12,72 \%$ & Educación & $2,33 \%$ \\
\hline Última página & $6,61 \%$ & & \\
\hline
\end{tabular}

Se trata de datos parciales, referidos a un único año (1995) y un único periódico (El País), por lo que hay que considerarlos con la debida cautela. Sólo un seguimiento más amplio permitiría generalizar sobre ese $12,61 \%$ de traducciones publicadas en dicho medio, que en el tiempo transcurrido desde 1995 puede haber variado sustancialmente. Sin embargo, se trata de una cuantificación única y rigurosa, y supone un punto de arranque para establecer el volumen de traducciones en la prensa española. Este último aspecto, además, se revela de sumo interés si consideramos que en ocasiones ni siquiera las propias empresas periodísticas poseen datos sobre la cantidad de textos traducidos que publican ${ }^{3}$ o al menos así lo manifiestan.

En lo referente al diario El Mundo, se han publicado igualmente trabajos que ofrecen datos parciales sobre la cantidad de información traducida (Hernández Guerrero 2008a; 2008b; 2010). Los datos recabados muestran el uso de la traducción en las secciones de Opinión, Internacional y Ciencia a lo largo de uno o varios años, así como análisis descriptivos de cómo se lleva a cabo el trasvase transcultural de la información periodística en este periódico.

Estos estudios ponen de relieve que en la prensa española de información general la traducción forma parte del proceso de generación de contenidos de prácticamente todas las secciones, si bien se observa un peso mayor en algunas secciones concretas, como es el caso de Opinión e Internacional. La cuantificación es una parte destacada del proceso de análisis del material traducido, el cual permite profundizar en la política de traducción que siguen los medios y sacar a la luz otros parámetros, como, por ejemplo, hasta qué punto unas culturas influyen sobre otras, de qué lenguas se traduce, cuáles son las sociedades exportadoras de información, etc. 
Como muestra de la utilidad y necesidad de la cuantificación, paso previo para determinar el volumen de traducción y poder analizarlo, vamos a servirnos de los datos obtenidos en un estudio nuestro llevado a cabo sobre las traducciones publicadas en la sección de Opinión durante el año 2004 en las dos principales cabeceras españolas, El País y El Mundo (Hernández Guerrero 2008a), cuyo resultado, reflejado en la siguiente tabla, permite sacar a la luz una información de gran interés, inexistente hasta ese momento: el volumen de traducción en dichos periódicos y el análisis y comparación de los datos obtenidos.

TABLA 3

Porcentaje de artículos traducidos publicados en la sección de Opinión de los diarios El País y El Mundo en 2004. Fuente: Hernández Guerrero (2008a)

\begin{tabular}{|l|c|c|c|c|}
\hline & $\begin{array}{c}\text { Colaboraciones } \\
\text { en español }\end{array}$ & $\begin{array}{c}\text { Colaboraciones } \\
\text { traducidas }\end{array}$ & $\begin{array}{c}\text { Total } \\
\text { colaboraciones }\end{array}$ & $\begin{array}{c}\text { Porcentaje de } \\
\text { traducciones }\end{array}$ \\
\hline EL PAÍS & 620 & 150 & 770 & $19 \%$ \\
\hline EL MUNDO & 229 & 86 & 315 & $27 \%$ \\
\hline
\end{tabular}

En el año 2004, El País publicó en sus páginas de opinión un total de 770 artículos de colaboradores externos. De esos 770 artículos, 150 eran traducciones, lo que representa aproximadamente un $19 \%$ del total ${ }^{4}$.

Esos 150 textos traducidos pertenecen a 82 articulistas diferentes, lo que implica que algunos de ellos repiten. Es el caso de André Glucksmann, Gilles Kepel y Joseph S. Nye, con seis artículos cada uno; o Joseph E. Stiglitz, Predrag Matvejevic, Paul Kennedy y Alain Touraine, que publicaron en cinco ocasiones; o Barbara Probs Solomon, Sami Naïr, Jeremy Rifkin, Timothy Garton Ash, Jean Daniel y Norman Birnbaum, cuatro veces. Por solo citar los autores traducidos que con mayor frecuencia aparecen en estas páginas.

Por lenguas, hay que destacar el predominio del inglés (87 artículos en total), pues una gran parte de los colaboradores son estadounidenses y, algunos, ingleses; seguido del francés (37 artículos), del italiano (8 artículos) y otras lenguas como el alemán (3), el árabe (3), el portugués (2) y el ruso (2), además de ocho artículos traducidos de los que, por la falta de datos que presentan, no identificamos su lengua de partida, aunque probablemente se trate de traducciones del inglés.

Todos estos artículos traducidos se presentan al lector con la misma imagen (formato, extensión, elementos de titulación, tipografía, etc.) que el resto de colaboraciones que figuran en las páginas de opinión, escritas originalmente en español. La única diferencia entre esos textos y los traducidos es que éstos últimos incluyen en el pie de autor una información adicional: el nombre del autor de la traducción y en ocasiones el copyright indicando el medio de procedencia.

El País suele publicar de 2 a 4 colaboraciones diarias, frente a una única colaboración en El Mundo (bajo la rúbrica Tribuna Libre) de lunes a sábado, lo que explica las diferencias en las cifras entre uno y otro periódico. De las 315 colaboraciones publicadas por El Mundo en 2004, 86 eran textos traducidos.

Sin embargo, en términos porcentuales, el número de traducciones publicadas por El Mundo es mayor, aproximadamente un 27\% (frente al 19\% observado en el otro medio). Estos 86 artículos traducidos han sido escritos por 68 articulistas diferentes, lo que implica la presencia frecuente de algunos de ellos; es el caso de la 
sexóloga estadounidense Shere Hite (11 artículos) o el escritor británico Frederick Fortsyth (5).

Por lenguas, apreciamos de nuevo el predominio absoluto del inglés (68 artículos), con una presencia testimonial del francés (6) y del italiano (4). En 8 casos no hemos podido identificar la lengua del original ante la falta de datos. Y es que, si bien estas traducciones se presentan a los lectores con el mismo formato, tipografía, etc. que el resto de colaboraciones de la Tribuna Libre, no añaden, como en el caso de El País, un pie de texto con datos acerca de la traducción (como pueden ser el nombre del autor de la traducción, el medio de procedencia, la lengua de la que se ha traducido, etc.). La falta de esos datos no sólo dificulta el rastreo del original, sino que desde un punto de vista más amplio supone una falta de transparencia hacia los lectores del diario, que acceden a estos textos traducidos sin la información pertinente al respecto.

El hecho de importar opiniones foráneas es un indicador de la importancia que estos periódicos conceden a los acontecimientos internacionales y a su interés por obtener otros puntos de vista, de diversa procedencia, que en líneas generales son seleccionados porque se hallan próximos a la línea ideológica defendida en sus páginas. Es cierto que la solicitación de opinión a voces internacionales supone una postura concreta de apertura al exterior, que contrasta, por ejemplo, con la de otros diarios nacionales ( $A B C$, La Razón) donde muy esporádicamente se recurre a la traducción de artículos de opinión. Los datos analizados -que sólo se refieren a dos diarios y un único año, 2004, por lo que deben considerarse con la debida cautelamuestran claramente el enorme peso que tienen las firmas de prestigio anglosajonas. La gran mayoría de estos textos se traduce del inglés, con una presencia testimonial del francés, el italiano y otras lenguas, como reflejo de lo que también está ocurriendo en otros ámbitos, como el literario, el científico, el audiovisual, etc. La supremacía estadounidense convierte a esta sociedad en la principal exportadora de opinión.

\section{Conclusiones}

Resulta difícil condensar y exponer en estas breves páginas toda la complejidad del fuerte vínculo existente entre periodismo y traducción. La respuesta a las seis preguntas periodísticas - siete, si añadimos el aspecto cuantitativo- nos ha permitido ofrecer un acercamiento global a la desconocida realidad de la traducción periodística en la prensa española de información general.

A guisa de conclusión, destacamos que en la prensa española la traducción es un instrumento indispensable para obtener y generar nueva información y este hecho la convierte en una de las piezas clave en la cadena de producción periodística. Ese carácter instrumental le confiere un uso muy flexible que, en ocasiones, se aleja de los conceptos tradicionalmente establecidos por la teoría de la traducción. Así, muchos de los textos traducidos en la prensa escrita no persiguen representar a otro texto previo, no es esa su finalidad. Los mediadores que los producen no actúan como simples intermediarios en el trasvase transcultural, sino que adoptan un papel más activo y operan como productores. Sus miras están puestas en la nueva función que debe cumplir el texto que están produciendo para un marco comunicativo y un medio nuevos, y recurren a una amplia gama de transformaciones necesarias para esos fines. 
No muestran fidelidad a los textos de los que parten, sino a lo que hay que hacer con el texto que están produciendo.

Las nuevas necesidades de los canales receptores -los periódicos- determinarán el tratamiento que recibirá la información procedente de otros medios y el modo en que se presentará a la audiencia, siempre teniendo en cuenta que los usos difieren en gran medida dependiendo del periódico que se analice. No es difícil hallar desde traducciones stricto sensu que responden al concepto tradicional que se tiene del término, hasta traducciones que solo reproducen parte del original, pasando por prácticas como la utilización de la información traducida para la elaboración de otras noticias o diferentes tipos de reescritura que se sirven de la traducción, todo ello dependiendo de la consideración que reciba el original: si es una fuente estable o inestable.

La actividad traductora es una pieza fundamental del proceso de transmisión de la información. Sin embargo, debe ser vista como una parte más del complejo proceso de elaboración de la información, pues el objetivo final de los medios al servirse de la traducción no es presentar textos traducidos en el sentido tradicional del término, sino la producción de artículos periodísticos.

El proceso traductor queda diluido en el proceso periodístico. La invisibilidad y la transparencia de las traducciones periodísticas ocultan la presencia de la actividad traductora en la prensa española. A ello contribuye que los periódicos españoles no siempre indican las fuentes de las que se sirven y la mayor parte de las traducciones se presenta sin la firma del traductor. En lo referente a la recepción de estas traducciones, hay medios -los menos- que presentan la información traducida como tal, es decir, incluyendo marcas que indican al lector que está leyendo una traducción; algunos adoptan posturas intermedias y sólo en el caso de algunos géneros periodísticos incluyen esas marcas; otros, de manera sistemática, ocultan esa información.

No queremos concluir sin antes señalar que en el ámbito de la traducción periodística son necesarios muchos más estudios para componer un panorama más preciso de la actividad traductora. Así, por ejemplo, se debe prestar una mayor atención a la producción, desarrollo, estructura y recepción de la información traducida, al volumen de traducción en todas las publicaciones y los modos de uso de la traducción en el ámbito periodístico. Todo ello con un claro objetivo: profundizar en la descripción de la función de la traducción periodística en una situación sociocultural receptora concreta. Y es que la prensa escrita española supone un excelente observatorio para el estudio del comportamiento real de la traducción en un ámbito profesional apenas explorado, con interesantes implicaciones desde el punto de vista periodístico, traductológico y sociológico.

\section{NOTAS}

1. Aunque con diferentes denominaciones, hay plena coincidencia al señalar la existencia de estos tres géneros periodísticos. No se puede decir lo mismo en lo relativo a los subgéneros. Basta con echar un vistazo a la bibliografía sobre el tema para comprobar que algunas variedades textuales son híbridas y figuran, según el investigador consultado, en un género u otro. Lo mismo ocurre en los libros de estilo de los principales periódicos nacionales (Libro de estilo de ABC (1993): Barcelona: Ariel; Libro de estilo de El Mundo (1996): Madrid: Temas de Hoy; Libro de estilo de El País (1996): Madrid: Ediciones El País; Libro de estilo de La Vanguardia (1986): Barcelona: La Vanguardia). Así, por ejemplo, en el Libro de estilo de El Mundo (1996: 23) leemos a propósito de la entrevista: "Se puede considerar como un subgénero de la información básica o noticia. En este caso, su único 
objetivo es informar de las opiniones de alguien." Sin embargo, Martínez de Sousa (2003: 39), en el Libro de estilo de Vocento, incluye este subgénero dentro de los géneros interpretativos.

2. Tomamos los términos fuente estable e inestable de Pym (2004: 174-176), quien asocia la unstable source a los textos producidos en esta era de comunicación electrónica, constantemente sujetos a actualizaciones y adaptaciones, en una situación semejante a la vivida antes del descubrimiento de la imprenta, cuando los textos originales eran manuscritos que se transformaban con cada nueva copia, cuando los traductores gozaban de gran libertad para introducir notas, glosas, en un constante proceso de reescritura que iba dejando huella en los textos.

3. El estudio de González Rodríguez incluye una entrevista de 1997 con el entonces responsable de Relaciones Externas de El País, Miguel Ángel Bastenier, quien, a la pregunta de: “'Tiene su diario estadísticas sobre el porcentaje de artículos traducidos?", responde con un escueto "no" (1999: 304).

4. Este porcentaje es similar al que ofrecía González Rodríguez (1999) para el año 1995, un 19,62\%, lo que permite aventurar que unos diez años después El País sigue manteniendo un volumen de traducción equivalente en su sección de Opinión.

\section{REFERENCIAS BIBLIOGRÁFICAS}

Alonso, María (2004): El caso de la traducción en El País. Saltana 1. Biblioteca de Traductores. Consultado el 27 de octubre de 2006, <http://www.saltana.org/biblib/files/pais.pdf >.

Bielsa, Esperança y BAssnett, Susan (2008): Translation in Global News. Londres y Nueva York: Routledge.

CASAsús, Joseph Maria y NúÑEz LADEvéZE, Luis (1991): Estilo y géneros periodísticos. Barcelona: Ariel.

Cortés Zaborras, Carmen y Hernández Guerrero, María José, eds. (2005): La traducción periodística. Cuenca: Ediciones de la Universidad de Castilla-La Mancha.

Frías Arnés, José Francisco (2005): Traducción y periodismo: El País English Edition. Puentes. 1:39-46.

Gomis, Lorenzo (1991): Teoría del periodismo. Barcelona: Paidós.

González Rodríguez, Antonio (1999): La traducción en la prensa: "El País, 1995". Tesis de doctorado. Madrid: Universidad Complutense. Consultado el 15 de febrero de 2008, <http:// www.ucm.es/eprints/3989/>.

Gutiérrez de Terán, Ignacio (1997): Manual de traducción periodística (del español al árabe). Madrid: Cant Arabia.

Hernández Guerrero, María José (2004): La traducción de los titulares periodísticos. In: José Suso López y Rodrigo López Carrillo, eds. Le français face aux défis actuels. Histoire, langue et culture. Granada: Universidad de Granada-Apfue-Gilec, 271-281.

Hernández Guerrero, María José (2005a): La traducción de los géneros periodísticos. In: Carmen Cortés Zaborras y María José Hernández Guerrero, eds. La traducción periodística. Cuenca: Ediciones de la Universidad de Castilla-La Mancha, 89-135.

Hernández Guerrero, María José (2005b): Prensa y traducción. In: Carmen Cortés Zaborras y María José Hernández Guerrero, eds. La traducción periodística. Cuenca: Ediciones de la Universidad de Castilla-La Mancha, 157-175.

Hernández Guerrero, María José (2006): El recurso a la traducción compilada en la prensa escrita. In: Pilar Blanco y Pilar Martino, eds. Traducción y multiculturalidad. Madrid: Universidad Complutense, 365-374.

Hernández Guerrero, María José (2008a): Los artículos de opinión traducidos en la prensa escrita: el trasvase transcultural de la opinión. In: María José Hernández Guerrero y Martín Salvador Peña, eds. La traducción, factor de cambio. Berna: Peter Lang, 93-113.

Hernández Guerrero, María José (2008b): La traducción de la información científica en la prensa española: el diario El Mundo. Sendebar. 19:167-187.

Hernández Guerrero, María José (2010): Las noticias traducidas en el diario El Mundo: el trasvase transcultural de la información. In: Roberto VALDEón, ed. Translating Information. Oviedo: Universidad de Oviedo, 51-85. 
Hernández Guerrero, María José (en prensa): La actividad traductora en la prensa escrita: el recurso a la reescritura. In: Actas de los XII Encuentros Complutenses en torno a la Traducción (Madrid, 17-19 de abril de 2008).

López Guix, Juan Gabriel (2005): Traducir para la prensa escrita: reflexiones de un traductor. In: Ana Sofía Ramírez, ed. El texto de opinión en la prensa escrita. Su tratamiento en la traducción. Las Palmas de Gran Canaria: Universidad de Las Palmas de Gran Canaria, 105-118.

Martínez, Claudia (2001): Traducción y periodismo. Actas del III Congreso Latinoamericano de Traducción. Buenos Aires: Colegio de Traductores Públicos de la Ciudad de Buenos Aires. Consultado el 10 de diciembre de 2005, <http://www.traductores.org.ar>.

Martínez Albertos, José Luis (1989): El lenguaje periodístico. Madrid: Paraninfo.

Martínez Albertos, José Luis (2000): Curso general de redacción periodística. Madrid: Paraninfo.

Martínez de Sousa, José (2003): Libro de estilo de Vocento. Gijón: Trea.

Muro Benayas, Ignacio (2006): Globalización de la información y agencias de noticias. Barcelona: Paidós.

Núñez Ladevéze, Luis (1993): Métodos de redacción y fundamentos de estilo. Madrid: Síntesis.

NúÑEZ LADEvÉZE, Luis (1995): Introducción al periodismo escrito. Barcelona: Ariel.

Orengo, Alberto (2005): Localising News: Translation and the "Global-national" Dichotomy. Language and Intercultural Communication. 5(2):168-187.

Pym, Anthony (2004): The Moving Text: Localization, Translation, and Distribution. Amsterdam: John Benjamins.

Stetting, Karen (1989): Transediting. A New Term for Coping with the Grey Area between Editing and Translating. In: Graham Caie, Kirsten HaAstrup, Arnt Lykke Jakobsen, et al., eds. Proceedings from the Fourth Nordic Conference for English Studies. Copenhagen: University of Copenhagen, 371-382.

Stinson de Quevedo, Mirta (2001): Journalistic Translation: some basic assumptions. Bitácora: Revista de la Facultad de Lenguas. 7(4):115-122.

Tapia Sasot de Coffey, María Josefina (1992): La traducción en los medios de prensa. Babel. 38(1):59-63.

VIDAL, José Manuel (2005): Algunas vivencias de un traductor de prensa. In: Carmen CoRTÉs Zaborras y María José Hernández Guerrero, eds. La traducción periodística. Cuenca: Ediciones de la Universidad de Castilla-La Mancha, 379-390.

Vuorinen, Erkka (1995): News Translation as Gatekeeping. In: Mary Snell-Hornby, Zuzana JetTmarová and Klaus KaINDL, eds. Translation as Intercultural Communication. Amsterdam and Philadelphia: John Benjamins, 161-172. 